\title{
Effects of 1-p-chlorobenzyl-1 $H$-indazol-3-carboxylic acid (AF 1312/TS) on the fertility of rats
}

\author{
P. Scorza Barcellona, V. Cioli, S. Burberi and B. Silvestrini \\ F. Angelini Research Institute, Viale Amelia 70, Rome, Italy
}

The indazolcarboxylic acids are compounds which have been shown to have antispermatogenic activity (Corsi, Palazzo, Germani, Scorza Barcellona \& Silvestrini, 1976). The prototype of the series, 1-p-chlorobenzyl-1 $H$-indazol-3-carboxylic acid or AF 1312/TS, produces changes in the rat seminiferous epithelium within $24 \mathrm{~h}$ of a single oral dose. It affects the spermatids, spermatocytes and Sertoli cells without producing any lesions of the spermatogonia or interstitial tissue (De Martino et al., 1975; Silvestrini et al., 1975). Prolonged treatment, up to 6 months in the rat, has shown that the substance has no toxic effects or any adverse effects on the accessory sex organs of adult animals (Burberi, Catanese, Cioli, Scorza Barcellona \& Silvestrini, 1975).

The present study was performed to assess the effects of AF 1312/TS on fertility in male and female rats, and to verify the reported difference between prepubertal and mature rats in their sensitivity to the drug.

The experiments were performed on Long-Evans rats given AF 1312/TS orally. For the males, the substance was incorporated in the diet because of the prolonged treatment required. A $0.5 \%$ concentration, previously proved to affect the rat seminiferous epithelium (Burberi et al., 1975), was used. Female rats were treated with AF 1312/TS by gavage at a daily dose of $500 \mathrm{mg} / \mathrm{kg}$ suspended in a $0.5 \%$ methylcellulose solution and administered in a volume of $10 \mathrm{ml} / \mathrm{kg}$. Dosage by this route and at this level has been shown to produce severe germinal aplasia in male rats after only $\mathbf{5}$ daily administrations (Silvestrini et al., 1975). The significance of the results was assessed by Student's $t$ or $\chi^{2}$ tests.

\section{Males}

The effects on male fertility were studied in two experiments lasting altogether 21 weeks. In Exp. 1, two groups of 5 mature rats were treated with a medicated or normal diet for 8 weeks. From the start of treatment, each male was housed with two virgin untreated females from 17.00 to $09.00 \mathrm{~h}$, the diet being removed from the cages during this period. Vaginal smears were examined each day until spermatozoa were found; the mated female was then isolated. This procedure continued for 5 days each week, 2 new females being used after each weekend. The inseminated females were killed on the 19th day after mating. All other females were isolated at the end of each week and killed after 21 days. Each uterus was examined for viable and resorbing fetuses and then processed according to the method of Salewski (1964) for detection of deciduomata. The fetuses were individually weighed and examined.

In Exp. 2, groups of 10 mature males were fed the medicated diet as in Exp. 1 or a normal diet (controls). The animals were allowed to mate from the 9 th to 21 st week of treatment and fertility was assessed as in Exp. 1.

The results of these two experiments are shown in Table 1 . The first case of sterility occurred in the 4th week and from that week onwards the number of fertile males decreased steadily, only one being still fertile by Week 19 . The ratio between pregnant and inseminated females and the mean litter size dropped at the 9 th week. During the first weeks of sterility the semen found in the vaginal smears appeared normal, but subsequently spermatozoa with shortened and thinned flagella appeared. Copulation was sometimes observed after several weeks of sterility. There were no differences between the pregnant females in the control and treated groups in the numbers of implantation sites, resorptions and malformations or in fetal weights.

For the study of prepubertal males, 35-day-old animals (10 treated, 10 control) were used. The experiment lasted for 9 weeks. During the last week, each male was housed with 2 virgin untreated 
Table 1. Effects of a diet containing $0.5 \%$ AF $1312 / \mathrm{TS}$, fed throughout the experimental period for $8 \mathrm{~h} /$ day, on the fertility of male rats

\begin{tabular}{|c|c|c|c|c|c|c|}
\hline \multirow[b]{2}{*}{ Week } & \multicolumn{3}{|c|}{ Control rats } & \multicolumn{3}{|c|}{ Treated rats } \\
\hline & $\begin{array}{l}\text { No. of fertile } \\
\text { males/no. of } \\
\text { treated males }\end{array}$ & $\begin{array}{l}\text { No. of pregnant } \\
\text { females/no. of } \\
\text { inseminated } \\
\text { females }\end{array}$ & $\begin{array}{c}\text { Litter size } \dagger \\
(\text { mean } \pm \text { S.E.M.) }\end{array}$ & $\begin{array}{l}\text { No. of fertile } \\
\text { males/no. of } \\
\text { treated males }\end{array}$ & $\begin{array}{l}\text { No. of pregnant } \\
\text { females/no. of } \\
\text { inseminated } \\
\text { females }\end{array}$ & $\begin{array}{c}\text { Litter size } \dagger \\
(\text { mean } \pm \text { S.E.M. })\end{array}$ \\
\hline 1 & $5 / 5$ & $6 / 6$ & $11.3 \pm 0.49$ & $5 / 5$ & $8 / 8$ & $10.7 \pm 0.70$ \\
\hline 2 & $4 / 5$ & $6 / 6$ & $10.2 \pm 0.54$ & $5 / 5$ & $8 / 9$ & $9.0 \pm 1.26$ \\
\hline 3 & $5 / 5$ & $7 / 7$ & $11.3 \pm 0.52$ & $5 / 5$ & $7 / 8$ & $8.4 \pm 1.57$ \\
\hline 4 & $5 / 5$ & $7 / 7$ & $10.7 \pm 0.81$ & $4 / 5$ & $8 / 10$ & $8.6 \pm 1.74$ \\
\hline 5 & $5 / 5$ & $7 / 8$ & $9.1 \pm 1.44$ & $3 / 5$ & $6 / 8$ & $7.5 \pm 1.78$ \\
\hline 6 & $5 / 5$ & $6 / 8$ & $8 \cdot 1 \pm 1.88$ & $4 / 5$ & $8 / 9$ & $11.0 \pm 1.41$ \\
\hline 7 & $5 / 5$ & $7 / 9$ & $9 \cdot 1 \pm 1 \cdot 90$ & $4 / 5$ & $6 / 8$ & $7.0 \pm 1.81$ \\
\hline 8 & $5 / 5$ & $8 / 9$ & $9.3 \pm 1.39$ & $4 / 5$ & $5 / 6$ & $8.5 \pm 1.93$ \\
\hline 9 & $8 / 10$ & $12 / 14$ & $9 \cdot 0 \pm 1 \cdot 14$ & $5 / 10$ & $8 / 16^{*}$ & $4.7 \pm 1.26^{*}$ \\
\hline 10 & $8 / 10$ & $14 / 16$ & $8.7 \pm 0.98$ & $5 / 10$ & $6 / 16^{* *}$ & $3 \cdot 7 \pm 1 \cdot 30^{* *}$ \\
\hline 11 & $8 / 10$ & $12 / 15$ & $8.7 \pm 1.22$ & $5 / 10$ & $3 / 11^{*}$ & $2 \cdot 5 \pm 1 \cdot 37^{* *}$ \\
\hline 12 & $7 / 10$ & $11 / 13$ & $8.8 \pm 1.21$ & $3 / 10$ & $4 / 13^{*}$ & $3 \cdot 1 \pm 1 \cdot 36^{* *}$ \\
\hline 13 & $8 / 10$ & $12 / 16$ & $7.9 \pm 1.23$ & $3 / 10$ & $5 / 11$ & $4.4 \pm 1.57$ \\
\hline 14 & $8 / 10$ & $10 / 13$ & $8.3 \pm 1.35$ & $3 / 10$ & $5 / 10$ & $5.4 \pm 1.86$ \\
\hline 15 & $9 / 10$ & $15 / 16$ & $10.2 \pm 0.75$ & $3 / 10^{*}$ & $3 / 5$ & $7 \cdot 6 \pm 3 \cdot 11$ \\
\hline 16 & $8 / 10$ & $11 / 19$ & $6.2 \pm 1.29$ & $3 / 10$ & $3 / 15$ & $1.9 \pm 1.02^{*}$ \\
\hline 17 & $9 / 10$ & $13 / 15$ & $8.4 \pm 0.98$ & $2 / 10^{* * *}$ & $3 / 9^{*}$ & $3 \cdot 1 \pm 1.58^{* *}$ \\
\hline 18 & $8 / 10$ & $11 / 16$ & $6.6 \pm 1.22$ & $2 / 10^{*}$ & $3 / 8$ & $3.6 \pm 1.79$ \\
\hline 19 & $9 / 10$ & $13 / 15$ & $9.2 \pm 1.05$ & $1 / 10^{* *}$ & $1 / 13^{* * *}$ & $0.9 \pm 0.92^{* * *}$ \\
\hline 20 & $8 / 10$ & $12 / 12$ & $9.8 \pm 0.79$ & $1 / 10^{* *}$ & $1 / 7^{* *}$ & $1.3 \pm 1.29 * * *$ \\
\hline 21 & $9 / 10$ & $12 / 14$ & $8.6 \pm 1.07$ & $1 / 10^{* *}$ & $1 / 6^{* *}$ & $2 \cdot 0 \pm 2 \cdot 00^{* *}$ \\
\hline
\end{tabular}

Significantly different from controls: ${ }^{*} P<0.05 ;{ }^{* *} P<0.01 ;{ }^{* * *} P<0.001$.

$\dagger$ Calculated by dividing the total no. of viable fetuses by the no. of inseminated females.

females from 17.00 to $09.00 \mathrm{~h}$ in a cage without food. The behaviour of the animals was observed for the first hour of cohabitation. Fertility was assessed by allowing the females to litter. No adverse effects of treatment on sexual behaviour were observed. All the males showed interest in the females; moreover, repeated mating was observed in 5 treated males but only in 4 controls. All the female rats in the control group were fertile, but none of those mated by treated males littered.

\section{Females}

Two groups of reproductively mature females (172-278 g) were treated with AF 1312/TS (16 rats) or with the vehicle alone (10 rats) for 15 days. Treatment was continued and on the 16 th day each female was housed with an untreated male of proven fertility from 17.00 to $09.00 \mathrm{~h}$ the following day. A vaginal smear was taken daily after removing the male rat from the cage. This procedure was repeated until spermatozoa were found in the smear (up to 10 days). The animal was then treated once more and isolated until parturition was due. The young in the litter were counted and examined. After weaning the mothers were killed, the uterus was treated by the Salewski (1964) method and the implantation sites were counted. Mild ataxia and irritability were observed in the treated females. In those treated with AF 1312/TS, the ratio between pregnant and inseminated females was 11/15 compared with $8 / 10$ in the control group and the average litter sizes were 7.9 and 10.4 respectively. The mean number of implantation sites was 9.3 in the treated animals and 11.2 in the controls. None of these results was statistically significantly different. No abnormalities in the newborn were observed in either group. In the control group, mating was completed within 3 days, whereas in the group treated with AF 1312/TS mating continued up to the 10th day. There were no differences in oestrous cycle lengths, as determined by vaginal smear results, of the treated and control rats. 


\section{Discussion}

The present results show that AF 1312/TS, at a concentration of $0.5 \%$ in the diet, produces antifertility effects from the 4th week of treatment. The finding that sterility did not occur simultaneously in all the animals may be due to differences in sensitivity to the compound, as reported for male rats by Burberi et al. (1975). These differences may have been accentuated by individual differences in food intake (not measured) and by the fact that, in contrast to the previous experiment (Burberi et al., 1975), the animals were treated with the medicated diet for 8 instead of $24 \mathrm{~h}$ daily.

The difference in sensitivity to the drug between prepubertal and mature rats (Burberi $e t$ al., 1975; Silvestrini et al., 1975) was confirmed. Treatment of the perpubertal rats produced sterility in all animals by the 8 th week, whereas only $50 \%$ of the mature treated rats became sterile during the same period.

The antifertility effect on the male seems to be unrelated to interference with sexual behaviour, as shown by the occurrence of many sterile inseminations and by the normal mating behaviour. The longer time needed for the treated females to mate may have been related to behavioural disturbances provoked by the high dosage used. However, the small reduction in implantation sites and litter size was without any statistical significance. Although a slight interference with female reproductive function cannot be excluded, a comparison of the results obtained in males and females show a clear sex difference in the response to the drug.

These experiments were supported by a grant from the Consiglio Nazionale delle Ricerche (C.N.R.).

\section{References}

Burberi, S., Catanese, B., Cioli, V., Scorza BarcelLONA, P. \& Silvestrini, B. (1975) Antispermatogenic activity of 1-p-chlorobenzyl-1 $H$-indazol-3-carboxylic acid (AF 1312/TS) in rats. II. A study of treatments of duration between 5 and 180 days. Exp. molec. Path. 23, 308-320.

Corsi, G., Palazzo, G., Germani, C., Scorza BarCellona, P. \& Silvestriñ, B. (1976) 1-Halobenzyl$1 \mathrm{H}$-indazol-3-carboxylic acids. A new class of antispermatogenic agents. J. med. Chem. 19, 778783.

De Martino, C., Stefanini, M., Agrestini, A., Cocchia, D., Morelli, M. \& Scorza Barcellona, P. (1975) Antispermatogenic activity of 1-p-chloro- benzyl-1 $H$-indazol-3-carboxylic acid (AF 1312/TS) in rats. III. A light and electron microscopic study after single oral doses. Exp. molec. Path. 23, 321-356.

Salewsk1, E. (1964) Färbemethode zum makroskopischen Nachweis von Implantations-stellen am Uterus der Ratte. Naunyn-Schmiedeberg's Arch. exp. Path. Pharmak. 247, 367.

Silvestrini, B., Burberi, S., Catanese, B., Cloli, V., Coulston, F., Lisciani, R. \& Scorza Barcel. P. (1975) Antispermatogenic activity of 1-p-chlorobenzyl-1 $H$-indazol-3-carboxylic acid (AF 1312/TS) in rats. I. Trials of single and short-term administration with study of pharmacologic and toxicologic effects. Exp. molec. Path. 23, 288-307. 